\title{
Surgical Treatment of Gynaecomastia: A Prospective Study in 75 Patients
}

\author{
Adel M. Tolba, Mohamed Nasr \\ Plastic Surgery Unit, General Surgery, Zagazig University, Zagazig, Egypt \\ Email: abdelrahmantolba@yahoo.com
}

Received 29 September 2015; accepted 13 November 2015; published 16 November 2015

Copyright (C) 2015 by authors and Scientific Research Publishing Inc.

This work is licensed under the Creative Commons Attribution International License (CC BY). http://creativecommons.org/licenses/by/4.0/

(c) (i) Open Access

\begin{abstract}
Introduction: Gynaecomastia is a benign enlargement of male breast; many techniques have been described for management but none have gained universal acceptance. We discuss the outcomes of the surgical management of gynaecomastia and assess the morbidity and complication rates associated with the procedure to determine whether certain surgical techniques produce better outcomes. Materials and Methods: 75 patients with gynaecomastia were operated in our hospital during the period from Jan. 2009 to Jan. 2015. Results: A total of 140 breasts were operated on during the study period. Patients underwent either liposuction alone (20 breasts), excision alone (70 breasts), both excision and liposuction (36 breast) or skin reduction procedure (14 breasts). 19 operated breasts (13.4\%) experienced some form of complications. Minor complications included seroma (4 patients), superficial wound dehiscence ( 3 patients) and two patients developed haematomas requiring evacuation in theatre. Unsatisfactory cosmotic result was present in 10 breasts and surgical revision was done in 5 breasts. Simon grade 111 breasts experienced the highest complication rate. Conclusion: The study has found that moderate sized gynaecomastia whether true or pseudo gynaecomastia with mild to moderate breast redundancy can be managed easily and effectively by liposuction alone or combined with glandular resection while the conventional infraareolar subcutaneous mastectomy still gives satisfactory results and with no need to remove extra skin. On the other hand, large gynaecomastia with severe breast redundancy can be treated effectively by the inferior pedicle technique without vertical scar.
\end{abstract}

\section{Keywords}

Gynaecomastia, Male Breast, Surgical Management

\section{Introduction}

The incidence of gynaecomastia in men is $32 \%$ - 65\% [1]. Gynaecomastia is usually caused by a hormonal im- 
balance as may be seen postnatally, during puberty, and in the elderly. Most cases of GM are idiopathic, although, pathological etiologies need to be ruled out; these include congenital and endocrine disorders, tumors, and drugs. Gynaecomastia may be unilateral or bilateral, symmetrical or asymmetrical. Pain or tenderness may or may not be present. In contrast to the male breast cancer, which is usually present as a hard mass with or without skin changes and may occupy a central or peripheral location it is usually centrally located [2].

Gynaecomastia treatment should be individualized according to the patient's needs and expectations as well as the specific indication for surgery [3]. Surgery is indicated for patients with gynaecomastia that does not regress spontaneously or, with medical therapy, or causing considerable discomfort or psychological distress or is long-standing (beyond a 18 - 24-months period) [4]-[6].

The current surgical options for gynaecomastia are subcutaneous mastectomy, suction-assisted lipectomy, or a combination of these approaches that are performed with different technologic devices and surgical methods [7]. Resection with skin reduction is generally added to the surgical procedure in Simon's grade III gynecomastia [6]. In spite of the variety of methods and tools used in gynecomastia surgery, in mild gynacomastia the results are satisfactory while severe gynaecomastia presents a surgical challenge [8]. As some postoperative frustrating problems still cannot be completely eliminated. The most common of these are a saucer-like deformity (over resection under areola), bleeding, followed by seroma, infection, ischaemic necrosis of nipple-areola complex residual gynaecomastia (under resection), persistence of inframammary fold, contour irregularities, and asymmetries between breasts [9].

In this study, we aim to discuss the outcomes of the surgical management of the gynaecomastia and assess the morbidity and complication rates associated with the procedure to determine whether certain surgical techniques produce better outcomes.

\section{Patients and Methods}

The current study was carried out at Plastic surgery unit of Zagazig University Hospitals, Egypt, during the period from Jan. 2009 to Jan. 2015. It includes 75 patients that were presented by gynacomastia. Patients with chronic liver and renal disease, hyperthyroidism, alcoholics and patients on medical treatment as anabolic sterroids were excluded.

For the purpose of this study, we considered each operated breast as an individual case.

Patient demographics, the grade of gynaecomastia, the presence of skin excess, causative factors, duration of symptoms and surgical procedure were recorded. Short and long-term minor and major complications, poor results, and revision rates were recorded and analysed.

Each patient completed an assessment sheet evaluating their satisfaction with surgery, recording overall satisfaction, appearance of scars and improvement in chest shape and self confidence, with a linear score out of a maximum of 10 .

An informed consent about surgery, possible outcome, and complications was obtained. This study was approved by the IRB of Zgazig University Hospitals.

\section{Operative Techniques}

Pre-operative marking of the patient in the upright position and under general anaesthesia, the breast tissue was infiltrated with a solution of normal saline, 1\% lignocaine and 1:1000 adrenaline. All patients received one dose of intra-operative intravenous broad-spectrum antibiotics.

\subsection{Procedures without Skin Reduction}

\subsubsection{Excision through Semicircular Peri-Areolar Incision}

A semicircular incision extending from 3 o'clock to 9 o'clock along the inferior margin of the areola was used. Through this incision, the whole glandular tissue was excised, apart from a 1-cm disk that was left on the undersurface of the areola to avoid the "saucer" deformity. The tissues were closed in layers with absorbable sutures (Figure 1 \& Figure 2).

\subsubsection{Liposuction}

Suction assisted liposuction (SAL). 


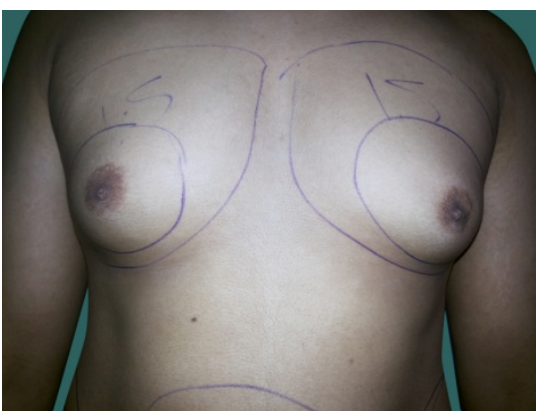

(a)

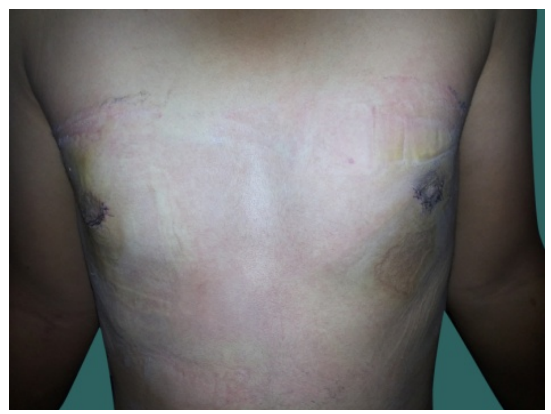

(b)

Figure 1. (a) Preoperative; (b) postoperative.

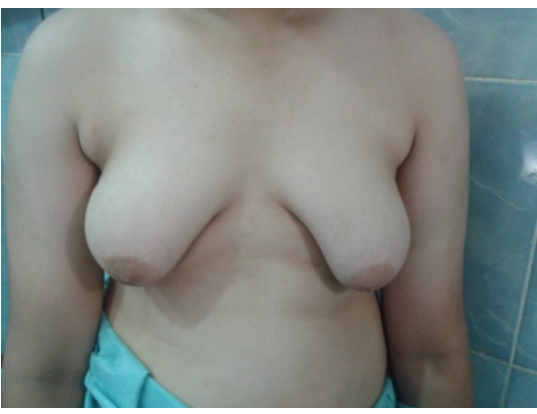

(a)

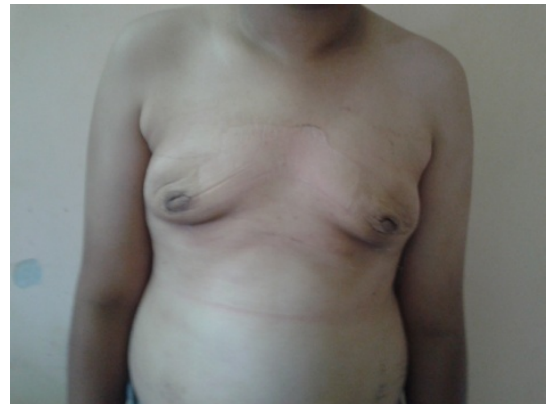

(b)

Figure 2. (a) Preoperative; (b) postoperative.

After a super wet/tumescent infiltration of the breast tissue by the previously mentioned infiltrate, liposuction started by continuous movement of the cannula in fanlike long strokes, starting deep and working superficially ,with special effort to disrupt the inframammary fold. The endpoint was determined by loss of tissue resistance and appearance of the aspirate (Figure 3).

Laser assisted liposuction (LAL).

The $600-\mu \mathrm{m}$ laser fiber cannula was introduced (The fiber was adjusted so as to protrude from the tip of the cannula by approximately $2 \mathrm{~mm}$.The system used was a 1064-nm wave length ND laser (Fotona XP2, Solovania) at a power of $15 \mathrm{~W}$ with continuous emission, and $8-12 \mathrm{~kJ}$ total average accumulated energy per breast. Laser energy emission was directional following the plane of the cannula. Care was taken that the cannula was moved back and forth in two fat tissue planes whenever the laser was actuated. First, the cannula was passed in a deep plane, followed by a faster movement in a more superficial skin layer. Care was taken not to stop the movement of the cannula. If the cannula was stopped and irradiation was continued, there was a risk that the skin surface would burn. When acting on a superficial plane, hand movements were careful and quicker in the areola/nipple complex area to avoid damage of the vascular pedicle. After the procedure, aspiration was performed at 1 bar negative pressure with the 1-mm cannula previously used for tunneling (Figure 4).

\subsection{Skin Reduction Procedures}

\subsubsection{Complete Concentric Circumareolar Approach "Benelli Type"}

Marking of the midline, sternum, infra-mammary folds and areola was done with the patient in upright position. In case of wide areolae, the areola was marked to a diameter of 25 - $30 \mathrm{~mm}$. A concentric or mildly eccentric, (in case the nipple needed to be lifted) circum-areolar incision (14 - 20 mmwide) was marked to include the epidermal "doughnut", which was then resected. Under general anaesthesia, the "doughnut" shaped epidermal ring was de-epithelialized, followed by a semicircular inferior transdermal incision within the de-epithelialized area extending from 3 to 9 o'clock position. Then the excessive glandular tissue was excised, adequate thickness under the nipple was left to avoid areolar retraction or ischemia. The breast skin was sutured to the areola inverting the de-epithelized segment in 2 layers. An additional 2/0 PDS intradermal circumareolar purse-string suture was used to decrease the diameter of the breast skin border and to decrease the tension on the suture line was used in 


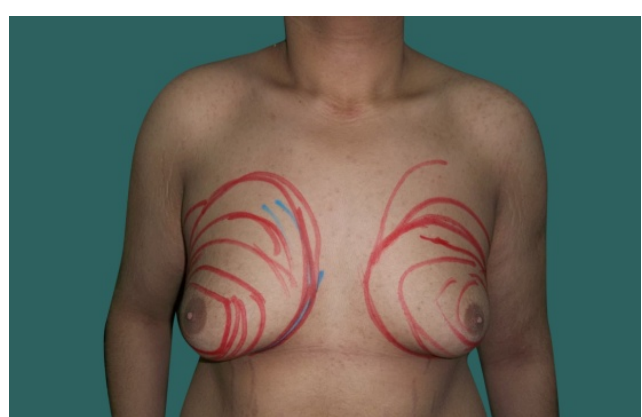

(a)

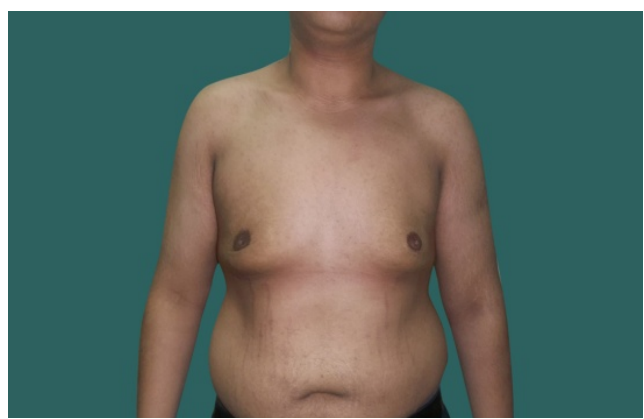

(b)

Figure 3. (a) Preoperative; (b) postoperative.

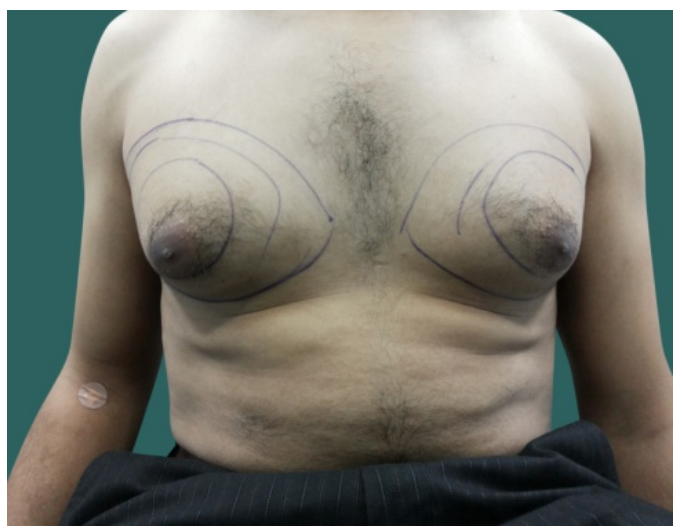

(a)

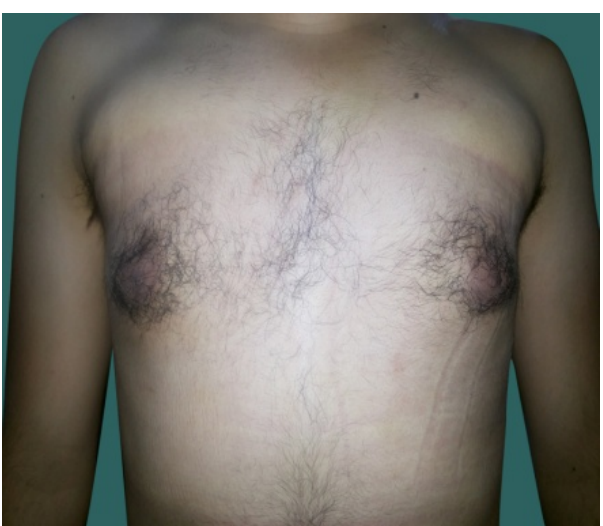

(b)

Figure 4. (a) Preoperative; (b) postoperative.

some cases.

\subsubsection{Inverted T (Modified Wise) Pattern Scar}

Gynaecomastia with severe ptosis and excessive skin and tissue redundancy. A modified “wise pattern” inverted T approach was used. The new position of areola-inframammary fold was $3-3.5 \mathrm{~cm}$ and the blood supply to the nipple was maintained by inferior pedicle (Figure 5).

\subsubsection{Inferior Pedicle Technique without Vertical Scar}

The midline sternum was marked, as well as the inframammary crease lines. Vertical lines were drawn from the mid-clavicle and extended down to the inframammary crease, the pedicle was marked. With a scalpel, the pedicle is de-epithelialised and then elevated, the inframammary incision was made to the fascia of the muscle. Next, blunt digital dissection was performed. After complete elevation of the glandular tissue of the fascia, the flap was then pulled down in an inferior direction, in order to ascertain the exact amount of resection possible. It was important to avoid any undue tension with the planned amount of skin excision. The excess skin was then excised, with a resulting long horizontal incision. Excess glandular tissue would be excised at this point if any thinning of the flap is necessary. Closure of the incision was performed in layers. The new nipple site with a 3 $\mathrm{cm}$ areolar diameter was then marked on the skin at the level of the $4^{\text {th }}$ intercostal space in the midclavicular line in an even and symmetrical fashion bilaterally (Figure 6).

\subsection{A Combination of 2 Surgical Procedure}

Liposuction and subcutaneous mastectomy (Figure 7).

Following the procedure, suction drain for 3 - 5 days and a pressure dressing consisting of gauze was applied and held in place with microfoam tape. Patients were instructed to wear a pressure garment day and night for six weeks. Follow up was 3 - 9 months. 


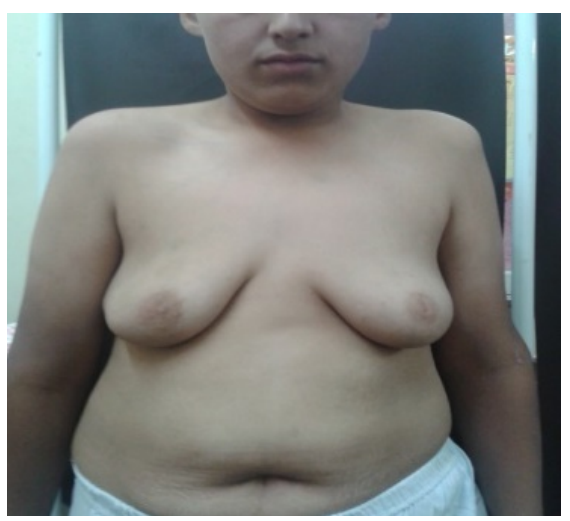

(a)

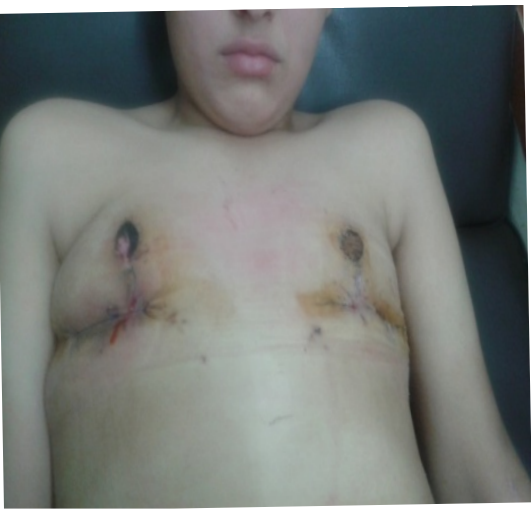

(b)

Figure 5. (a) Preoperative; (b) postoperative.

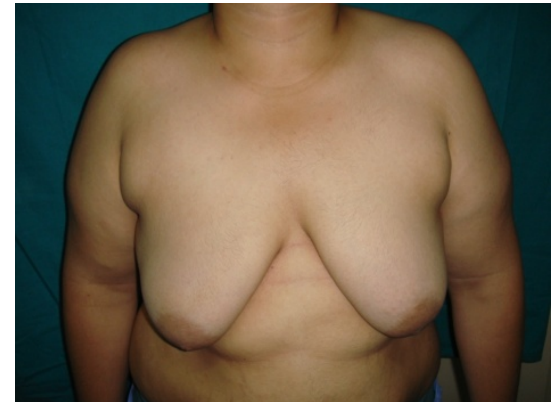

(a)

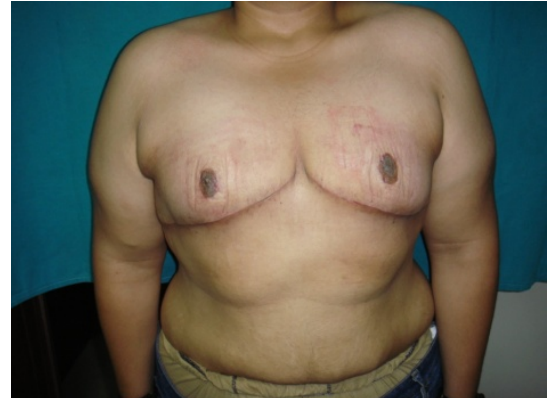

(b)

Figure 6. (a) Preoperative; (b) postoperative.

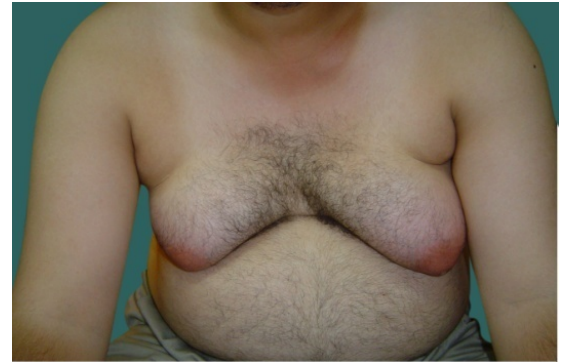

(a)

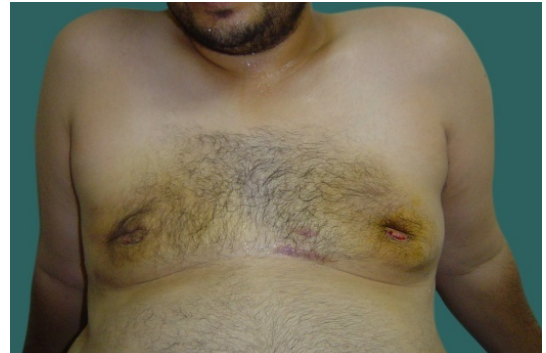

(b)

Figure 7. (a) Preoperative; (b) postoperative.

\section{Results}

75 patients and a total of 140 breasts were operated on during the study period. Patients were referred from a variable sources. General practitioners referred 25 (33.3\%) patients, 5 (6.6\%) were referred by the general surgical unit and 3 (4\%) from the paediatric unit while the other 42 patients seeks our plastic unit from the start (56\%). Ages ranged from 14 - 37 years (Mean 22.5 years). All patients cited emotional problems as the reason for them seeking help, except 2 who complained of pain and discomfort (Table 1).

Endocrine blood tests were performed 25 times (33.6\%). In some cases, those tests were performed by the referring physician. Breast imaging was used in 24 cases (32\%): 8 (10.6\%) had a mammography, 12 (16\%) had an ultrasound, and in 4 (5\%), both modalities were used. In 4 patients (5\%), systemic imaging was used to investigate the adrenals or the testes. None of the imaging yielded pathological findings. Fine-needle aspiration for cytology was performed in 3 patients (4\%) (Table 2 ).

The periareolar approach was used on 70 breasts, and a circumareolar skin reduction with subcutaneous 
Table 1. Age, body weight, duration of symptoms, grade of gynaecomastia.

\begin{tabular}{cc} 
Patient details & Results \\
Age & $14-37 \mathrm{y}(22.5$ Year $)$ \\
Body weight & $55-95 \mathrm{~kg}(63 \mathrm{~g})$ \\
Body mass index & $22-36$ (26) \\
Duration of symptoms & 6 y (2 - 17 year) \\
Grade of gynacomastia & \\
1 & 55 \\
$2 \mathrm{~A}$ & 25 \\
$2 \mathrm{~B}$ & 40 \\
3 & 20 \\
Side involved & $10 \mathrm{pt}$ \\
Unilateral & $65 \mathrm{pt}$ \\
Bilateral & \\
\hline
\end{tabular}

Table 2. Endocrinal blood tests and imaging.

\begin{tabular}{cc}
\hline Examination & Number of patients \\
\hline Endocrine blood test & $25(33.6 \%)$ \\
Imaging & \\
Mammogrm & $8(10.6 \%)$ \\
Breast ultrasound & $12(16 \%)$ \\
Mammogram and ultrasound & $4(5 \%)$ \\
Systemic imaging & $4(5 \%)$ \\
FNA & $3(4 \%)$ \\
\hline
\end{tabular}

mastectomy was used on 6 breasts. An inverted T pattern and inferior pedicle technique without vertical scar were performed each on 4 breasts. Liposuction alone was used on 20 breasts, and as an adjunct to periareolar approach on 36 breasts.

Tissue was submitted for histological examination in 15 breasts. There were no pathology results. No malignancies were found, but, atypical ductal epithelial hyperplasia was seen in 3 breasts of 2 patients.

19 operated breasts (13.4\%) experienced some form of complications. Minor complications included seroma (4 breasts) and superficial wound dehiscence treated conservatively (3 breasts). The only acute major complication encountered were haematomas requiring evacuation in theatre (2 breasts). Unsatisfactory result was present in 10 breasts and second gynacomastia surgery was needed in 5 breasts. The causes of the unsatisfactory cosmesis were equally distributed between nipple tethering or inversion, ugly scar and contour irrigularity (Table 3).

Analyses of the operative data showed that age of the patients, specimen weight, grade of gynaecomastia and the specific surgical approach used were not significant predictors of minor or acute major complications. However, it indicated that the grade of Gynaecomastia and weight of the specimen was a significant predictor of poor cosmosis Patients with grade III (7/40) gynaecomastia were more likely to have poor cosmetic results and need late revision operation than patients with grade I (1/35) and grade II (2/65) gynaecomastia. Comparing all approaches used for grade 111, it was found that the inferior pedicle without vertical scar gives the best cosmotic result and showed that the surgical approach used is a significant predictor for the cosmetic outcome. Finally, age was not found to be a significant predictor of the cosmetic outcome. We found that 65 patients (93\%) were very satisfied (score: 8 - 10) with their cosmetic outcome. One liposuction patients returned overall-satisfaction scores of less than eight. This patient was also less satisfied with the improvements in his chest shape and 
Table 3. Surgical approach, operative time, hospital stay and complications.

\begin{tabular}{cc}
\hline Surgical approach & \\
Liposuction & 20 breasts (14.2\%) \\
Periareolar approach & 70 breasts (50\%) \\
Circumareolar with skin resection & 10 breasts (7.1\%) \\
Inverted T & 4 breasts (2.8\%) \\
Liposuction plus periareolar & 36 breasts (25.7\%) \\
Operative time & 30 - 130 (60 minutes) \\
Weight of spicmen & $95-450(200$ gm) \\
Hospital stay & $1-2$ days \\
Minor complication & $7(5 \%)$ \\
Acute major complication & $2(1.4 \%)$ \\
Late non satisfactory & $10(7 \%)$ \\
\hline
\end{tabular}

self-confidence. The scars of all breasts treated by open excision were scored between 9 and 10, and those treated by skin reduction were scored between 5 and 7 .

\section{Discussion}

Gynaecomastia is classified into true gynaecomastia with proliferation of ducts and periductal tissues and Pseudogynaecomastia due to deposition of adipose tissue or to the presence of an excessive amount of skin [10]. The most common and practical classification is that of Hoffman and Simon who classified true gynacomastia into:

Grade 1: Minor enlargement and no redundant skin

Grade 2A: Moderate enlargement and no redundant skin

Grade 2B: Moderate enlargement and minor skin redundancy

Grade 3: Gross enlargement and major skin redundancy [11]

Three age groups are usually affected. The first one is in neonatal period $(60 \%-90 \%$ of infants have transient gynaecomastia due to transplacental transfer of oestrogen) [2] [12]. The $2^{\text {nd }}$ is during puberty (10 - 12 years) affecting $48 \%$ - 64\%. $90 \%$ of them resolves spontaneously before the age of 17 and only $10 \%$ persist. The highest prevalence is among middle aged and older man (50 - 80 years old), $40 \%-65 \%$ of whom are reported to have a degree of gynaecomastia that is often multifactorial [8] [11] [13]. The oldest patient in our study was 37 years old. This may be related to the fact that the cause for surgery in almost all cases was emotional distress, and older men may be less affected by this stimulus compared to the younger age group.

Surgery is considered when gynaecomastia present for more that 2 years as gynacomastia is unlikely to regress spontaneously or with medical treatment since the tissue is irreversibly fibrotic [14] [15]. Surgery is indicated to correct the deformity, restoring a normal body contour and image with maintaining the viability of the nipple-areola complex, avoiding excessive scarring and preventing a "saucer" deformity aiming to relieve emotional discomfort, psychosocial distress and intolerable pain [5].

A number of aesthetic surgical techniques are available for management of gynaecomastia and surgeons often find it difficult to choose the technique that will achieve the best results for a given patient [16]. Liposuction techniques are enough for some forms of gynaecomastia; others require open procedures using either intra-areolar or extra-areolar incisions [3].

On reviewing literature about the management of gynaecomastia Simon grade 1 and 2, it was found that liposuction is the technique of choice in non glandular cases (pseudo-gynaecomastia) .On the other hand, management of true gynaecomastia grade 1 and 2, includes subcutaneous mastectomy alone, liposuction alone or liposuction combined with subcutaneous mastectomy [17] [18]. The classic surgical approach with semicircular periareolar incision was described by Webster in 1946 and it is the ideal approach for mild and moderate gynaecomastia. Alternative to surgery, the suction-assisted lipectomy was introduced in 1970. While the Laser-assisted liposuction has been proven to be safe and effective for the treatment of gynecomastia [19]. For mild gy- 
naecomastia, all approaches seem to have similarly good results.

Many surgeons prefer subcutaneous mastectomy for the treatment of true gynaecomastia [20] [21]. Various incisions and techniques have been described for the treatment of gynaecomastia, the periareolar incision is the most commonly used techniques because the final scars are almost inconspicuous [22]. Decreased or absent nipple sensation, necrosis of the nipple-areola complex and skin, haematoma, seroma, infection, contour deformity, distorted shape of the areola, and retraction of the areola and skin are the most common complications of subcutaneous mastectomy [11].

In this study, subcutaneous mastectomy was done 70 cases with grade1, 2 gynaecomastia and several patients with moderate-to-large breasts, it was felt that the skin elasticity was sufficient, and thus no skin reduction was performed. One patient was left with a mild degree of redundant skin in the nipple-areolar complex (Figure 2). This did not affect the overall result, and extra-areolar scars were avoided. In this study, incidence of complications was 7 cases (10\%), 3 of them were minor complications in the form of seroma, and superficial wound dehiscence and these were managed in the outpatient clinic during the postoperative visits, haematoma which was evacuated in operating theatre, These complications did not affect the final cosmotic result while the other three cases were contour deformities and depression in the area of nipple and areola and surrounding area. 67 patients were very satisfied with their results, returning the highest scores for overall satisfaction, improvement of self-confidence and the shape of the chest. The longer semicircular scar at the periareolar margin was well accepted and usually faded with time.

Suction assisted lipectomy to gynaecomastia is easy and does not impair areolar vascularity or sensation, and because the postoperative scars are excellent. It permits more rapid, efficient and controlled tissue removal, facilitating consistently good results without some of the drawbacks of open surgical excision particularly contour irregularities. It also has decreased the incidence of haematoma. So far the advantages of this technique justify its use in almost all gynaecomastia procedures [23]. Bjorn found that glandular tissue was included in their aspirate. They concluded that "Tissue suction" is a very valuable technique for correcting most gynaecomastias and that the advantages of this technique justify its use in almost all gynaecomastia procedures. Although established for lipomatous pseudo gynaecomastia, value of liposuction for treating true glandular hypertrophy in male breasts is controversial [18]. several other authors [24] [25] have recommended liposuction for the treatment of true gynaecomastia but with the use of special cutting cannulas, these cannulas, however, are traumatic and make damage to blood vessels and nerves more likely.

In this work, 10 breasts with pseudo-gynacomastia were managed with suction assisted liposuction the entrance sites for liposuction were chosen in submammary crease and lower axilla as was stated by Coelman and colleagues [26] to allow crisscross tunneling. A small cannula $(3 \mathrm{~mm})$ was used to remove tissues in retroareolar region. As they can easily penetrate through the fibrous glandular tissue beneath the areola as recommended by Pitman .Surgeons believe that skin retrapping and retraction and thus reduction of skin envelop is maintained by intact connective tissue bands [23]. In this work, there was no postoperative skin redundancy even in the cases with mild to moderate skin excess.

The reported complications were three cases, two of them were seromae and the third was contoured formity. 9 patients were very satisfied with their results, returning the highest scores for overall satisfaction, improvement of self-confidence and the shape of the chest.

Laser-assisted lipolysis (LAL), introduced by Apfelberg in 1996 [27], has the advantages of excellent patient tolerance, quick recovery time, and the additional benefit of dermal tightening and is an excellent method for the treatment of lipodystrophy, mainly in difficult fibrous areas, such as gynaecomastia [28].

Ten breasts with grde 1 and 2 gyanacomastia were treated by Laser assisted liposuction (LAS). The postoperative period in all patients was incident-free. There were no signs of ischemia, skin burning, or loss of sensation in the nipple, and no infection, seroma or scarring was noted. Inspite of the small number of our study, we can conclude that LAL for gynecomastia is safe, and produces significant effects on fatty tissue with a reduction in volume of the breast, together with visible skin contraction. Provided an appropriate amount of energy is delivered by an experienced operator, the results are significant and consistent.

Suction assisted liposuction combined with open excision was first described by Teimourian and Perlman in 1983 [29] and has become one of the most widely used method foe management of gynaecomastia, because of the frequent difficulty of removing breast parenchyma by suction alone [30]-[32]. In order to have the best results, many surgeons choose direct excision of residual glandular tissue after completing the suction as the operation of choice for cases of true gynaecomastia [31] [33] [34].

This concept was adopted in this study for cases of true gynaecomastia grade 2 and several patients with 
moderate-to-large breasts it was felt that the skin elasticity was sufficient, and thus no skin reduction was performed.

In 36 breasts, liposuction was started then the breast was palpated for any significant residual glandular tissue, which is then removed through an inferior periareolar incision.

Suction in the non-glandular cases was found relatively easier than in the glandular cases because of the firm fibrous structure of the glandular breast enlargement [35]. This study agrees with this finding. Therefore, liposuction of gynaecomastia, the threshold for conversion to an open procedure should be low, because it is associated with a significant advantage for the patient. As it leads to a high degree of satisfaction and leaves the patient with a minimal almost invisible scar. The conversion to an open procedure is made intraoperatively [36]. Therefore, all patients undergoing liposuction need to consent for open excision as well. Although, open excision gives excellent results in smaller breast enlargements with distinct subareolar nodules, it is difficult to achieve a good result without liposuction in more diffuse enlargements and larger breasts as the pre-tunnelling and suction achieved with liposuction prior to open excision help to taper the peripheral contour, define the glandular tissue and make the excision easier.

The incidence of complications is nearly equal those of the conventional subcutaneous mastectomy, In this study, incidence of complications after liposuction was 4 cases (11\%), 2 of them were minor complications in the form of seroma, and marginal superficial sloughing of areola, and these were managed in the outpatient clinic during the postoperative visits. The other two cases were contour deformities in the form of depression in the area of nipple and areola and surrounding area. The cause of this deformity was, as explained by Pitman [23], due to failure to leave adequate soft tissue on the nipple areolar flap and surrounding skin, in open cases. These two cases were treated by secondary suctioning to taper the periphery.

For cases of severe gynaecomastia with redundant skin, many techniques have been described in literature they can be divided into two main groups: extra-areolar [37]-[39] and circumferential [40]-[42] excisions. Extraareolar skin excisions are, however, associated with hypertrophic scarring and unacceptable results [3] [22] [43]. Many authors suggested circumareolar skin excision. A concentric circle of periareolar skin is de-epithelialized and breast tissue can be resected through an infra-areolar incision [44] [45]. The final scar is limited to a circle at the periphery of the areola. The appearance of the scar is inferior to the semicircular periareolar scar, but it is well accepted by the patients. Liposuction can be also combined with a concentric mastopexy [18]. 6 breasts were operated by this technique, three developed complications in the form of seroma, haematoma and ugly scar as the skin surrounding the nipple-areolar complex was wrinkled, because the width of the circle of skin excised was too large. Therefore, this procedure is limited to a certain amount of skin excess.

The common techniques used for mastopexy and breast reduction for the female patient may also be used for the male, although the residual scars or the nipple deformities may cause more distress to the patients [8].

Superiorly or inferiorly based pedicle areolar flaps and free nipple techniques have been described for stage 3 gynaecomastia [3] [11] [16]. Le Jour has popularised a vertical mammaplasty technique without submammary scar for mastopexy and reduction of the female breast [46]. Apart from the circumferential scar, the breast is left with only a small vertical scar.

The inverted T technique was applied to 4 breasts with a high rate of unacceptable or unsatisfactory outcomes and it should be reserved only for those patients with insufficient skin elasticity because the technique is associated with less optimal cosmetic results.

Inferior pedicle technique without vertical scar was done for 4 breasts with severe gynaecomastia and excess skin This procedure is easy, simple and if compared to the concentric circumareolar skin excision, the latter does not give satisfactory skin excision in Simon grade 3 with marked skin redundancy in addition to the difficulty of excision of such a big breast tissue through an infrareolar incision. The main disadvantage of this procedure is the long transverse scar. All the cases done in this study were satisfied. They were all told before the operation that they will have a long transverse scar, and they all agreed without hesitation.

Our study has several weaknesses: There were differences in the numbers of patients treated by the different disciplines and the study describes patients who were operated for GM and does not report on patients who were not suitable for surgery, following the preoperative examination and workup, due to a reversible cause of GM such as anabolic steroid use or patients with chronic diseases such as liver failure.

\section{Conclusions}

Surgery is indicated after patient assessment and discussion of their expectation as surgery may yield unsatis- 
factory cosmetic results especially in moderate and severe gynaecomastia. In the latter, further revisional surgery is possible.

The surgical approach appears to be the most important predictor for good cosmesis with those gynaecomastias amenable to skin resection. Unrealistic expectations or unwillingness to accept the risks associated with surgery should be a contraindication for surgery.

Liposuction is an effective method of treatment of gynaecomastia grade 1,11 because it is easy, does not impair areolar vascularity or sensation, and because the postoperative scars are excellent. It also permits rapid, efficient and controlled tissue removal, and gives good cosmetic results but still the subcutaneous mastectomy with the infraareolar incision is widely used with good cosmotic results and high patient satisfaction.

In grade 1, 2 gynaecomastia, differentiation between fatty and glandular cases preoperative is not important since both cases can be treated by the same technique which is liposuction and surgical resection of residual glandular tissue in true gynaecomastia.

Laser Assisted Liposuction for gynecomastia is safe procedure, and has significant effects on fatty tissue with a reduction in volume of the breast, together with visible skin contraction.

The inferior pedicle without transverse scar technique for the management of Simon grade 3 gynaecomastia is a simple easy and satisfactory method for treatment of these severe cases and avoiding the difficulty and less satisfactory results of other breast reduction techniques.

\section{References}

[1] Yavuz, M., Kesiktas, E., Kesiktas, N.N. and Acartürk, S. (2006) Lighted Retractor-Assisted Transaxillary Approach in Gynecomastia Correction. Annals of Plastic Surgery, 57, 370-373. http://dx.doi.org/10.1097/01.sap.0000222567.04635.3b

[2] Bembo, S.A. and Carlson, H.E. (2004) Gynecomastia: Its Features, and When and How to Treat It. Cleveland Clinic Journal of Medicine, 71, 511-517.

[3] Kornstein, A.N. and Cinelli, P.B. (1992) Inferior Pedicle Reduction Technique for Larger Forms of Gynecomastia. Aesthetic Plastic Surgery, 16, 331-335.

[4] Riefkohl, R. and Courtiss, E.H. (1992) Gynecomastia. In: Georgiade, N.G., Georgiade, G.S. and Riefkohl, R., Eds., Textbook of Plastic Maxillofacial and Reconstructive Surgery, Vol 2, 2nd Edition, Williams \&Wilkins, Baltimore, 877-882.

[5] Colombo-Benkmann, M., Buse, B., Stern, J. and Herfarth, C. (1999) Indications for and Results of Surgical Therapy for Male Gynecomastia. The American Journal of Surgery, 178, 60-63. http://dx.doi.org/10.1016/S0002-9610(99)00108-7

[6] Cordova, A. and Moschella, F. (2008) Algorithm for Clinical Evaluation and Surgical Treatment of Gynaecomastia. Journal of Plastic, Reconstructive \& Aesthetic Surgery, 61, 41-49. http://dx.doi.org/10.1016/j.bjps.2007.09.033

[7] Hammond, D.C. (2009) Surgical Correction of Gynecomastia. Plastic and Reconstructive Surgery, 124, 61e-68e. http://dx.doi.org/10.1097/PRS.0b013e3181aa2dc7

[8] Wiesman, I.M., Lehman Jr., J.A., Parker, M.G., Tantri, M.D. and Wagner, D. Sperithelial Incision for the Surgical Treatment of Gynecomastia. Annals of Plastic Surgery, 54, 130-1344.

[9] Pedersen, J.C. (2004) Gynecomastia: An Outcome Analysis. Annals of Plastic Surgery, 53, 97-101.

[10] Letterman, G.L. and Schurter, M. (1986) Suggested Nomenclature for Aesthetic and Reconstructive Surgery of the Breast. Part III: Gynaecomastia. Aesthetic Plastic Surgery, 10, 55-57. http://dx.doi.org/10.1007/BF01575270

[11] Celebioglu, S., Ertas, N.M., Ozdil, K. and Oktem, F. (2004) Gynecomastia Treatment with Subareolar Glandular Pedicle. Aesthetic Plastic Surgery, 28, 281-286. http://dx.doi.org/10.1007/s00266-004-1300-1

[12] Rohrich, R.J., Ha, R.Y., Kenkel, J.M. and Adams Jr., W.P. (2003) Classification and Management of Gynecomastia: Defining the Role of Ultrasound-Assisted Liposuction. Plastic \& Reconstructive Surgery, 111, 909-923. http://dx.doi.org/10.1097/01.PRS.0000042146.40379.25

[13] Aslan, G., Tuncali, D., Terzioglu, A. and Bingul, F. (2005) Periareolar-Transareolar-Perithelial Incision for the Surgical Treatment of Gynecomastia. Annals of Plastic Surgery, 54, 130-134. http://dx.doi.org/10.1097/01.sap.0000143513.77819.7a

[14] Braunstein, G.D. (2007) Clinical Practice. Gynecomastia. The New England Journal of Medicine, 357, 1229-1237. http://dx.doi.org/10.1056/NEJMcp070677

[15] Persichetti, P., Berloco, M., Casadei, R.M., Marangi, G.F., Di Lella, F. and Nobili, A.M. (2001) Gynecomastia and the Complete Circumareolar Approach in the Surgical Management of Skin Redundancy. Plastic \& Reconstructive Sur- 
gery, 107, 948-954. http://dx.doi.org/10.1097/00006534-200104010-00007

[16] Botta, S.A. (1998) Alternatives for the Surgical Correction of Severe Gynaecomastia. Aesthetic Plastic Surgery, 22, 65-70. http://dx.doi.org/10.1007/s002669900168

[17] Rosenberg, G.J. (1987) Gynecomastia: Suction Lipectomy Ascontemporary Solution. Plastic \& Reconstructive Surgery, 80, 379-386. http://dx.doi.org/10.1097/00006534-198709000-00007

[18] Stark, B., Grandel, S. and Spilker, G. (1992) Tissue Suction of the Male and Female Breast. Aesthetic Plastic Surgery, 16, 317-324. http://dx.doi.org/10.1007/BF01570694

[19] Fruhstorfer, B.H. and Malata, C.M. (2003) A Systematic Approach to the Surgical Treatment of Gynaecomastia. British Journal of Plastic Surgery, 56, 237-246. http://dx.doi.org/10.1016/s0007-1226(03)00111-5

[20] Noer, H.H., Soe-Nielsen, N.H., Gottlieb, J. and Partoft, S. (1991) Gynecomastia Treated by Subcutaneous Mastectomy Using Webster's Method. Ugeskrift for Laeger, 153, 578-580.

[21] Steele, S.R., Martin, M.J. and Place, R.J. (2002) Gynecomastia: Complications of the Subcutaneous Mastectomy. The American Surgeon, 68, 210-213.

[22] Colonna, M.R., Preis, F.W.B., Ponzielli, G., Cavallini, M., Giovannini, U.M. and Leo, A.D. (1999) Gynecomastia: Diagnosticand Surgical Approach in the Treatment of 61 Patients. Annali Italiani di Chirurgia, 70, 699-702.

[23] Pitman, G.H. (1993) Breast and Chest Wall. In: Pitman, G.H., Ed., Liposuction and Aesthetic Surgery, Quality Medical Publishing, Inc., St. Louis, 197-215.

[24] Samdal, F., Kleppe, G. and Aabyholm, F. (1991) A New Suction Assisted Device for Removing Glandular Gynecomastia. Plastic \& Reconstructive Surgery, 87, 383-384. http://dx.doi.org/10.1097/00006534-199102000-00039

[25] Graf, R., Auersvald, A., Damasio, R.C.C., Rippel, R., de Arau, L.R.R., Bigarelli, L.H.C. and Franck, C.L. (2003) Ultrasound-Assisted Liposuction: An Analysis of 348 Cases. Aesthetic Plastic Surgery, 27, 146-153. http://dx.doi.org/10.1007/s00266-002-1516-x

[26] Coleman, W.P., Letessier, S. and Hanke, C.W. (1997) Liposuction. In: Coleman, W.P., Hanke, C.W., Alt, T.H. and Asken, S., Eds., Cosmetic Surgery of the Skin, Mosby, St. Louis.

[27] Apfelberg, D.B. (1996) Results of Multicenter Study of Laser-Assisted Liposuction. Clinics in Plastic Surgery, 23, 713-719.

[28] Mordon, S., Eymard-Maurin, A.F., Wassmer, B. and Ringot, J. (2007) Histologic Evaluation of Laser Lipolysis: Pulsed 1,064-nm ND:YAG Laser versus CW-980 nm Diode Laser. Aesthetic Surgery Journal, 27, 263-268. http://dx.doi.org/10.1016/j.asj.2007.03.005

[29] Teimourian, B. and Perlman, R. (1983) Surgery for Gynaecomastia. Aesthetic Plastic Surgery, 7, $155-157$. http://dx.doi.org/10.1007/BF01571338

[30] Lewis, C.M. (1985) Lipoplasty: Treatment for Gynaecomastia. Aesthetic Plastic Surgery, 9, 287-292. http://dx.doi.org/10.1007/bf01571048

[31] Courtiss, E.H. (1987) Gynecomastia: Analysis of 159 Patients and Current Recommendations for Treatment. Plastic \& Reconstructive Surgery, 79, 740-750. http://dx.doi.org/10.1097/00006534-198705000-00010

[32] Gasperoni, C., Salgarello, M. and Gasperoni, P. (2000) Technical Refinements in the Surgical Treatment of Gynaecomastia. Annals of Plastic Surgery, 44, 455-458. http://dx.doi.org/10.1097/00000637-200044040-00020

[33] Maldick, R.A. (1991) Gynaecomastia: Liposuction and Excision. Clinics in Plastic Surgery, 18, 815-822.

[34] Boljanovic, S., Axelsson, C.K. and Elberg, J.J. (2003) Surgical Treatment of Gynecomastia: Liposuction Combined with Subcutaneous Mastectomy. Scandinavian Journal of Surgery, 92, 160-162.

[35] Rigg, B.M. (1991) Morselization Suction: A Modified Technique for Gynecomastia. Plastic \& Reconstructive Surgery, 87, 159-160. http://dx.doi.org/10.1097/00006534-199107000-00029

[36] Abramo, A.C. (1994) Axillary Approach for Gynecomastia Liposuction. Aesthetic Plastic Surgery, 18, $265-268$. http://dx.doi.org/10.1007/BF00449792

[37] Letterman, G. and Schurter, M. (1972) Surgical Correction of Massive Gynecomastia. Plastic \& Reconstructive Surgery, 49, 259-262. http://dx.doi.org/10.1097/00006534-197203000-00003

[38] Brenner, P., Berger, A., Schneider, W. and Axmann, H.-D. (1992) Male Reduction Mammoplasty in Serious Gynecomastias. Aesthetic Plastic Surgery, 16, 325-330. http://dx.doi.org/10.1007/BF01570695

[39] Wray, R.C., Hoopes, J.E. and Davis, G.M. (1974) Correction of Extreme Gynaecomastia. British Journal of Plastic Surgery, 27, 39-41. http://dx.doi.org/10.1016/0007-1226(74)90060-5

[40] Davidson, B.A. (1979) Concentric Circle Operation for Massive Gynecomastia to Excise the Redundant Skin. Plastic \& Reconstructive Surgery, 63, 350-354. http://dx.doi.org/10.1097/00006534-197903000-00009 
[41] Perischetti, P., Berloco, M., Casadei, R.M., Marangi, G.F., Di Lella, F. and Nobili, A.M. (2001) Gynecomastia and the Complete Circumareolar Approach in the Surgical Management of Skin Redundancy. Plastic \& Reconstructive Surgery, 107, 948-954. http://dx.doi.org/10.1097/00006534-200104010-00007

[42] Huang, T.T., Hidalgo, J.E. and Lewis, S.R. (1982) A Circumareolar Approach in Surgical Management of Gynaecomastia. Plastic \& Reconstructive Surgery, 69, 35-40. http://dx.doi.org/10.1097/00006534-198269010-00005

[43] Simon, B.B., Hoffman, S. and Kahn, S. (1973) Classification and Surgical Correction of Gynecomastia. Plastic \& Reconstructive Surgery, 51, 48-52. http://dx.doi.org/10.1097/00006534-197301000-00009

[44] Davidson, B.A. (1979) Concentric Circle Operation for Massive Gynecomastia to Excise the Redundant Skin. Plastic \& Reconstructive Surgery, 63, 350-354. http://dx.doi.org/10.1097/00006534-197903000-00009

[45] Sarrabayrouse, M., Loustau, H. and Mayer, H.F. (2006) Versatility of the $360^{\circ}$ Periareolar Approach for the Treatment of Mammary Pathology. Aesthetic Plastic Surgery, 30, 9-14. http://dx.doi.org/10.1007/s00266-005-0072-6

[46] Lejour, M. (1994) Vertical Mammaplasty and Liposuction of the Breast. Plastic \& Reconstructive Surgery, 94, 100114. http://dx.doi.org/10.1097/00006534-199407000-00010 